\title{
E1 Ordenamiento Territorial como política de Estado
}

\author{
Land Planning as a State Policy
}

María Elina Gudiño ${ }^{1}$

Para citar este artículo, utilice el nombre completo así:

Gudiño, M. E. (2015). El Ordenamiento Territorial como política de Estado. Perspectiva Geográfica, 20(1), 11-36.

\section{Resumen}

El análisis crítico e interpretativo sobre el proceso de planificación en América Latina, como también el desarrollo de la experiencia de Argentina y Mendoza, en particular, fundamentan la necesidad de transformar al Ordenamiento Territorial en una verdadera política de Estado. Los cambios que se necesitan operar en la gestión dependen del grado de institucionalidad, gobernabilidad y gobernanza que se logre. Una política de Estado se construye a partir de consensos o, por lo menos, definiendo compromisos que deben plasmarse en acuerdos formales para llegar a un gran acuerdo, perdurable en el tiempo; es preciso poner por delante el interés común de la sociedad y los principios y fines del Ordenamiento Territorial. Si esto no se consigue, las transformaciones estructurales que la propia naturaleza del territorio exige, y que hoy reclama la sociedad, nuevamente fracasarán.

Palabras clave: gestión territorial, ordenamiento territorial, política de estado, políticas públicas.

1 Doctora en Geografía de la Universidad Nacional de Cuyo (UNCuyo); profesora titular efectiva de la Facultad de Filosofía y Letras, UnCuyo; investigadora independiente del CONICET, Argentina. marilyngudino@yahoo.com.ar 


\section{Abstract}

The critical and interpretive analysis of the planning process in Latin America, as well as the development of the experience of Argentina and Mendoza in particular, establishes the need to transform Territorial Planning into a true state policy. The changes that need to operate in the management depend on the grade of the institutionality, governability and governance that is achieved. A State policy is built on consensus or at least defining commitments to be translated into formal agreements to achieve a great deal. This is maintained over time, putting forward the common interests of society and the principles and purposes of Territorial Planning. If the structural transformations that the nature of the territory requires and the demands of society today are not achieved, they will fail again.

Keywords: land management, land planning, state policy, public policy. 


\section{Introducción}

El escenario actual de América Latina exige la implementación de nuevas estrategias que permitan alcanzar un desarrollo humano sostenible. Una de estas es la de convertir el Ordenamiento Territorial en una política de Estado para poder implementar acciones tendientes a revertir impactos negativos en el territorio.

Esta afirmación se fundamenta en dos hechos: los resultados de más de 40 años de historia de la planificación en América Latina y la debilidad que, actualmente, muestra el Estado frente al mercado, lo que se traduce en un aumento de los desequilibrios territoriales, iniquidades sociales y deterioro ambiental entre lo urbano y lo rural, en el sistema de ciudades en escala global, nacional y regional, y aún dentro de una misma ciudad:

En ciertos ámbitos tecnocráti$\cos \mathrm{y}$ académicos latinoamericanos, se observó una fuerte propensión a idealizar la capacidad de la planificación como instrumento para promover el desarrollo económico y social, propensión que se puede calificar como desmesurada si se la observa a la luz de los resultados que se lograron con su aplicación. De esa idealización da fehaciente testimonio una amplia literatura económica y sociológica de la época y, en particular, muchos documentos elaborados bajo el alero de organizaciones internacionales, como la Organización de los Estados Americanos (OEA), la CEPAL y el Instituto Latinoamericano de Planificación Económica y Social (ILPES) (De Mattos, 2005, p. 12).

Tal como lo señala Carlos De Mattos, la planificación no ha sido exitosa y muestra de ello es la persistencia de problemáticas estructurales que no logran resolverse, tales como concentración económica y disparidades regionales.

La formulación de políticas sectoriales y la aplicación de modalidades de planificación en las que no se tienen en cuenta al territorio, no han logrado atenuar las disparidades regionales ocasionadas por la lógica concentradora del mercado. Es por eso que, desde inicios del siglo XXI, la esperanza está puesta en el Ordenamiento Territorial, como técnica de planificación que permita abordar la naturaleza 
multi-escalar, sistémica e integral del territorio, lo que exige coordinación y coherencia en el accionar de las diferentes instituciones con competencia en el tema y en la formulación y ejecución de las políticas públicas para racionalizar el proceso de decisiones en el corto, mediano y largo plazo. Sin embargo, esto no ha sido así. La realidad demuestra que las políticas públicas aplicadas no tienen en cuenta la naturaleza holística y sistémica del territorio, la que fundamenta la necesidad de coordinación en su aplicación:

Los obstáculos no son de naturaleza cientifica, sino de gestión, planificación, ejecución y control de las instituciones competentes. (Vega Mora, 2008, p. 68)

Desde una perspectiva analítica, interpretativa y crítica se plantea la necesidad de producir cambios profundos en la manera de gestionar el territorio, los que dependen del grado de institucionalidad, gobernabilidad y gobernanza que se alcance. Se trata de condicionamientos que están implícitos en una política de Estado y constituyen parte de una estrategia para que esta modalidad de planificación no fracase y perdure en el tiempo.

\section{Fundamentos teóricos}

A partir de las últimas décadas del siglo XX, el Ordenamiento Territorial es objeto de una renovación conceptual y metodológica sin precedente. El cambio sustancial lo constituye la transición de un ordenamiento voluntarista, dirigido, centralizado en el Estado, hacia un ordenamiento coordinado y concertado entre distintos actores, aun cuando el que lidere el proceso sea el Estado por ser él que debe velar por el bien común. Al respecto, la Carta Europea de Ordenación del Territorio define al Ordenamiento Territorial, como:

...expresión espacial de la política económica, social, cultural y ecológica de toda la sociedad... una política concebida con un enfoque global, cuyo objetivo es el desarrollo equilibrado de las regiones y la organización física del espacio según un concepto rector, una nueva concepción de política, transversal a las politicas sectoriales, que permite concertar decisiones y coordinar acciones entre los sectores públicos, jurisdicciones territoriales y sectores privados y velar por el bien común promoviendo un desarrollo más 
sustentable, sostenible y socialmente más equitativo (Consejo de Europa 2008, p. 2).

La nueva concepción del Ordenamiento Territorial pone el acento no solo en el estudio interdisciplinario del territorio y la planificación, sino en la política y la gestión; es decir, en el juego de intereses y conflictos y en la construcción de consensos, como también en la necesidad de precisar a qué Estado se hace referencia, como entidad político-territorial para poder definir un nuevo tipo de política que permita gestionar el territorio de una manera más eficiente. Esto implica operar cambios profundos que solo se pueden hacer si se convierte el Ordenamiento Territorial en una verdadera política de Estado.

\subsection{El Estado como entidad terri- torial}

Como muchos conceptos centrales en las ciencias sociales, existe una verdadera polisemia referente al Estado, pero se puede encontrar tres nociones básicas en la literatura de la teoría política (Isuani, 1984), a saber:

- Como una asociación política o comunidad que incluye una institución de gobierno, por lo que Estado y gobierno no son idénticos. Max Weber, el representante más importante de esta teoría considera que la organización política gobernante se caracteriza por la territorialidad y la existencia de un órgano administrativo;

- como una dimensión de la sociedad más abstracta. Hegel, al respecto, menciona que el Estado no es el gobierno de una sociedad, sino una dimensión altamente abstracta de la sociedad que tiene que ver con la ética, lo universal y particular, la solidaridad y la identidad;

- como un aparato para el gobierno y la administración, posición sostenida por Karl Marx, para quien el Estado es básicamente un órgano separado de la sociedad, no es una dimensión abstracta, sino una institución concreta en las que la autonomía y la intervención adquieren significado.

En este caso, interesa el Estado como entidad político-territorial; una asociación política o comunidad asentada sobre un espacio determinado y organizada políticamente. (Méndez y Molinero, 1984). 
Se hace referencia al denominado Estado-Nación, el que supone una serie de elementos como: organización política, ordenamiento jurídico, aparato de gobierno, población y territorio y dos componentes básicos: la territorialidad o control de un espacio determinado y la comunidad organizada políticamente que se dota de un sistema de gobierno encargado de preservar su integridad territorial.

\section{Méndez y Molinero (1984)} destacan el criterio de organización territorial de los Estados, los que pueden clasificarse según el grado de descentralización del poder central en:

- Estado unitario o centralizado (en donde la soberanía no está dividida); tienen un único centro de poder, aunque es frecuente que haya cierta descentralización administrativa, por lo menos en el nivel municipal.

- Estado regional o autonómico es también un modelo frecuente, especialmente, en países en los que, debido a razones administrativas, históricas $\mathrm{y}$ democráticas, se crea unidades subestatales de cierta entidad. Existe autonomía política, aunque se trata de una sola soberanía nacional.

- Estado federal, modelo quizá más acorde con las necesidades descentralizadoras de algunos países para proteger la unidad nacional por encima de particularidades étnicas, lingüísticas e históricas. Este modelo, nacido de la Constitución norteamericana de 1787, plantea la superposición de dos estructuras: la Federación (sujeto soberano y garantía de unidad nacional) y los Estados miembros. Para Taylor (1994), el federalismo es quizá la forma más "geográfica" de Estado, ya que afronta más racionalmente las diferencias socioeconómicas en territorios muy extensos y los particularismos regionales.

- La Confederación es el modelo estatal en el que las relaciones con el poder central son más laxas. Mas bien, se trata de una unión de Estados soberanos con carácter más o menos permanente. La soberanía de cada Estado se mantiene, pero se renuncia a cierto poder en pro de una coordinación mayor entre varios para formar una entidad superior. Uno de los objetivos básicos de una confederación 
puede ser la defensa común para garantizar la seguridad externa e interna de los Estados.

\subsection{Políticas de Estado y políticas públicas}

Una política de Estado supone una orientación fundamental que conserva una cierta direccionalidad en el tiempo; difícilmente modificada más allá de la ideología de quien esté en el ejercicio del poder. La continuidad de estos grandes lineamientos funciona como un marco de acción que proporciona una relativa estabilidad y coherencia en la formulación y ejecución de las políticas públicas. Es por ello que, incluso, muchas veces la política de Estado es plasmada en el propio texto de la Constitución e integra en forma permanente la agenda gubernamental. No es una expresión jurídica, sino política. Es la manifestación más significativa de la capacidad de conducción del Estado. Forma parte de las estrategias centrales de un país, región autónoma o Estado federativo nacional o subnacional y se sostiene más allá del color político-ideológico de un Gobierno. Es por eso que trasciende la temporalidad de la gestión, la resolución de problemas de coyuntura y aún los de mediano alcance para tratar de definir criterios que resuelvan problemas de nivel estructural (Weber, 2007).

Cuando se habla de política de Estado se hace referencia a un tipo especial de política, dando por supuesto que existen otras de carácter más circunstancial, coyuntural o específicas relacionadas con una gestión gubernamental particular.

- "Una política de Estado, en la medida que trasciende a los partidos y a las ideologías, debería ser producto del consenso o de un gran acuerdo nacional que ponga por delante el interés del conjunto de la Nación" (Rulli, 2006).

- "Una política de Estado no puede pensarse como un programa rígido y estático en el tiempo, sino como el resultado complejo y cambiante de la combinación de fuerzas politicas, equilibrios sociales, historia y cultura" (Natanson, 2008).

- "Son estables y continuas. No dependen de los cambiantes humores políticos de los gobiernos, ni de las coyunturas electorales, sinoqueseapoyanen saberes técnicos y en consensos. 
Hoy, las politicas de Estado aparecen en muchas propuestas como un programa redactado por expertos y rubricado por políticos y en las antípodas del decisionismo. Combinan la ilusión tecnocrática con una dosis de otra ilusión: el consenso..." (Romero, 2010).

- Es una política que trasciende al gobierno que la inicia y continuada como un mandato por otros gobiernos que lo suceden, que fija cursos de acción que van a influir en la vida del Estado y de su propia sociedad y que supone un conjunto de acciones $y$ omisiones que manifiestan una determinada modalidad de intervención del Estado en relación con una cuestión que concita la atención, interés o movilización de otros actores en la sociedad civil" (Cueto \& Guardamagna, 2011, p. 14).

En este esquema, el Gobierno es el encargado de dirigir y conducir el Estado, a través de equipos de dirigentes y técnicos que se renuevan periódicamente y que tienen la responsabilidad de formular, implementar y ejecutar políticas a partir de un conjunto de normas, reglamentos, procedimientos y controles que, articulados por una cierta idea de lo que se puede y se debe hacer, constituyen las buenas prácticas de la administración o gestión.

Los gobiernos formulan politicas públicas que definen rumbos en sus principales áreas de actuación o gestión -educación, desarrollo económico, salud, política exterior, entre otras-. Generalmente, son sectoriales y no integrales, no siempre tienen en cuenta el dónde se implementan ni quiénes son los beneficiarios; pueden tener, o no, un amplio consenso social y político y perdurar, o no, en el tiempo, pero no necesariamente son políticas de Estado.

Toda política de Estado, para trascender en el tiempo, necesita el soporte de algún tipo de marco normativo. Sin embargo, no existe, necesariamente, una relación entre política y norma. La consolidación de una política de este tipo, implica, principalmente en democracia, atravesar múltiples conflictos, divergencias y contrariedades entre los actores. Esto es así porque el consenso no constituye un requisito primario para el diseño de la política de Estado, sino una suerte 
de "decantación" del proceso de construcción de la misma. Para tener políticas de Estado se requiere de un espacio o un campo político donde Estado y Sociedad se piensen entre sí y a sí mismos. Para ello, los gobiernos deben alentar una institucionalidad que facilite la circulación de los conflictos y del debate público que preceden la decisión política (Cueto \& Guardamagna, 2011).

Especialistas y tecnócratas opinan que las políticas de Estado son una utopía, pero lo cierto es que la sociedad reclama políticas de largo plazo, por lo que deben ser estables y continuas. Desde esta perspectiva, la política de Estado es un proceso de naturaleza conflictiva en el cual hay momentos en los que la lucha y el disenso dan paso a acuerdos, a instancias que ayudan a generar puntos de encuentro o, por lo menos, a aceptar que alguien, finalmente, logre imponer su visión y eso, transitoriamente, genera un orden.

El Ordenamiento Territorial debe ser una política de Estado, porque exige la combinación de fuerzas políticas y equilibrios sociales para la resolución de problemas estructurales e integrales del territorio, por ser el espacio de convergencia de poderes y porque la gestión exige saberes técnicos específicos y holísticos, la coordinación de las políticas públicas y un soporte normativo que trascienda en el tiempo.

\subsection{Institucionalidad, gobernabi- lidad y gobernanza}

No basta con enunciar una política de Estado; es necesario construirla entre todos y para poder hacerlo se necesita que exista respeto por las instituciones, lo que asegura una gobernabilidad. En un Estado de Bienestar estas dos condiciones bastaban para un buen gobierno, pero en el contexto actual se necesita, además, conciliar posiciones entre distintos actores, minimizar los conflictos a través de una mayor participación y avanzar hacia una mayor gobernanza.

La institucionalidad es entendida como un atributo básico del imperio o de la república, dentro de un estado de derecho. Cabe señalar que no existe completo consenso del alcance que se debe otorgar al término. En líneas generales, debe entenderse que una sociedad o un Estado tienen su institucionalidad más avanzada y fuerte, cuanto más eficientes sean las normativas y le- 
yes que se aplican, y cuanto menos distorsiones se verifiquen en las regulaciones y resoluciones. La institucionalidad se refiere a:

- El Estado de Derecho como instrumento de gobierno; que la ley sea capaz de guiar la conducta humana y que los poderes la interpreten y apliquen congruentemente y con las menores distorsiones posibles para facilitar las interacciones humanas y permitirla prevención y solución efectiva, eficiente $y$ pacífica de los conflictos.

- El Ordenamiento Jurídico, conjunto de normas que interactúan entre sí y que están interconectadas con base en principios de aplicación general.

- La Institucionalidad Política que regula la estructura y órganos del gobierno del Estado (Franco \& Székely Pardo, 2010).

Sin embargo, en la práctica, es posible comprobar la existencia de fragmentación institucional y desarticulación, lo que suele conducir a la descoordinación, a la duplicación $y$, por ende, al desperdicio de recursos.
Mientras exista mayor institucionalidad, se podrá construir mayor gobernabilidad, concepto relacionado con la capacidad de un buen gobierno. De acuerdo con la Organización de los Estados Americanos, para lograrlo se necesita:

- Estabilidad institucional y política.

- Efectividad en la toma de decisiones y la administración.

- Continuidad de las reglas y las instituciones, y consistencia e intensidad de las decisiones.

- Gobernanza, la que depende del nivel de madurez que alcance una sociedad organizada para asumir responsabilidades compartidas en la implementación de decisiones y en el arte de gobernar correctamente.

La estabilidad institucional y política se asegura con un Estado democrático, pero también con una clara distribución de competencias y responsabilidades; en tanto que la efectividad en la toma de decisiones y la administración depende de la eficacia y consistencia de las políticas, como también de la continuidad de las reglas e instituciones y del control de las acciones. 
La gobernabilidad exige un acuerdo de parte del poder político mientras que la gobernanza requiere un pacto entre el Gobierno y la Sociedad como miembros de una asociación política o comunidad que comparten poder.

La gobernanza es entendida como la capacidad de regular e intervenir teniendo en cuenta la coordinación de la multiplicidad de actores, para lograr un "buen gobierno". La idea es discutir colectivamente los problemas y arribar a soluciones. Se relaciona con el nivel de madurez que alcance la sociedad organizada para asumir responsabilidades compartidas.

La institucionalidad y la gobernabilidad son clave para el Ordenamiento Territorial por ser el Estado el que regula el accionar de distintas instituciones, a través de normas que definen los ámbitos de competencia y los modelos de organización y gestión; además porque es el responsable de hacer cumplir los principios de equilibrio, equidad y sostenibilidad tendientes al logro del bien común.

En el territorio confluyen, además, múltiples actores con diferentes tipos de intereses, por lo que la concurrencia de poderes plantea la necesidad de consolidar la gobernanza a través de una activa participación para poder construir consensos, a pesar de que no siempre los gobiernos están dispuestos a hacer partícipes de las decisiones a otros actores que inciden en el territorio.

\section{Etapas de la planificación en América Latina}

Más de 40 años de historia de la planificación en América Latina pueden ser sintetizados a través del análisis de la producción científica de investigadores reconocidos en el ámbito internacional, tales como Carlos De Mattos, especialista en planificación urbana (De Mattos, 1986) o Ángel Massiris, referente en el tema de las políticas territoriales (Massiris, 2001). También de autores como Martin Becerril-Padua y César Garcés que realizan un estudio sobre las contribuciones que realiza la CEPAL a los estudios del fenómeno urbano-metropolitano (Becerril - Pauda \& Garcés, 2004) y Pedro Felipe Montes, quien plantea al Ordenamiento Territorial, como opción de políticas urbanas y regionales en América Latina y el Caribe (Montes, 2001). 
A partir de los aportes de tales autores se puede reconstruir el proceso por el que ha transitado la planificación en este continente; proceso que ayuda a explicar el interés manifiesto en las últimas décadas por el Ordenamiento Territorial.

El proceso de adopción de la planificación en América Latina se inicia con la Conferencia realizada en Punta del Este, en 1961, y la creación de la Alianza para el Progreso. A partir de estos hechos se crean organismos de planificación y se elaboran planes nacionales de desarrollo en los que se incluye la planificación urbana física, conforme con los paradigmas teóricos prevalecientes.

Se trata de una planificación "desde arriba" que centra la atención en la morfología urbana y utiliza instrumentos provenientes de la Economía; por lo que el territorio es considerado de manera parcializada, no sistémica ni integral, dejando de lado otros aspectos vinculados con la función, la estructura y el proceso de aspectos sociales, políticos y ambientales.

En las décadas siguientes, la planificación urbano-regional intenta salvar este problema, mediante la transmisión de las directrices de desarrollo nacional a cada localidad a través del desglose de planes nacionales (sectoriales) en programas y proyectos. Pero la visión del territorio sigue siendo parcializada; se aplica metodologías diferentes para abordar lo urbano y lo regional, pero no se logra identificar relaciones, y sigue siendo una planificación sin oponentes; solo planifica el Estado, para lo cual se conforma sistemas de información estadística y se utiliza técnicas de programación económica.

Es decir que, durante mucho tiempo, la planificación sigue siendo normativa, tecnocrática, economicista, rígida y vulnerable a los cambios porque trabaja sistemáticamente con "sectores" y solo asistemática, parcial y secundariamente con "problemas" sin tener en cuenta la referencia territorial. En consecuencia, no atiende uno de los problemas clave que plantea la economía en el territorio, el de la concentración y los desequilibrios territoriales, por lo que no logra responder a las reales demandas sociales, generando iniquidades y deterioro ambiental.

A partir de 1980, el énfasis está puesto en el enfoque del eco-de- 
sarrollo impulsado por el Informe Brundtland, el que da lugar al documento: "Nuestra Propia Agenda sobre Desarrollo y Medio Ambiente" (Comisión de Desarrollo y Medio Ambiente de América Latina y el Caribe, 1991). En esta década se intensifica las políticas ambientales en países como Bolivia, Ecuador, El Salvador, Honduras, Nicaragua y República Dominicana, los que conciben el ordenamiento territorial como un instrumento de gestión ambiental (Massiris, 2008).

Desde esos años, en América Latina comienza a configurarse corrientes de pensamiento sobre estrategias alternativas para el desarrollo regional (Gudiño et al., 2013), así:

- la corriente contestataria; afirma que en elámbito de una economía capitalista no es posible pensar en la ejecución integral de estrategias conducentes a un verdadero desarrollo regional (Coraggio, 1981);

- la participativa; plantea la necesidad de aumentar la capacidad de negociación de las regiones y ampliar los niveles de participación en ellas, a través de la búsqueda de una mayor descentralización y reconocimiento de competencias propias a organismos de carácter regional, que no estén jerárquicamente subordinados al Estado nacional. (Boisier, S., 1985).

Poco a poco se plantea la necesidad de una planificación más flexible, estratégica, coordinada y concertada entre los diferentes actores sociales. En la década de los 90 surge, con fuerza, la Planificación Estratégica ante la presencia de un Estado debilitado y la necesidad de articular acciones entre el sector público, el privado y la sociedad.

El Estado ha sido el actor principal del proceso durante más de tres décadas y han prevalecido estructuras gubernamentales centralizadas, verticalistas y rígidas que aplicaron políticas públicas sectoriales parcializadas, lo que ha generado yuxtaposiciones de acciones de manera inorgánica y descoordinada en los distintos niveles de competencia jurisdiccional. La existencia de conflictos, divergencias e intereses particulares y sectoriales, que se resisten al cambio, plantea la necesidad de crear consensos y acuerdos, motivo por el cual el Ordenamiento Territorial se debe transformar en una verdadera política de Estado. 
3. EI Ordenamiento Territorial como política de Estado. Caso Argentina-Mendoza

En los últimos años del siglo XX, ante los efectos del neoliberalismo, se plantea la necesidad de redefinir el rol del Estado, hacer partícipes a otros actores y centrar la atención en el Ordenamiento Territorial, como forma de planificación multi-escalar, relacional, multidimensional, holística y sistémica, que puede abordar la realidad de una manera integral, lo que demanda una forma de gestión distinta, que coordine la acción de las distintas instituciones con competencia en el territorio.

Es necesario... diseñar nuevas estrategias de gestión y realizar cambios en las condiciones socioeconómicas y de cultura de planificación que hagan posible el éxito de la política de Ordenamiento Territorial (Massiris, 2002, p. 19).

Frente a problemas no resueltos y a las transformaciones que ocasiona el neoliberalismo en los territorios surge el Ordenamiento Territorial, como forma de planificación que puede minimizar los impactos negativos, mediante la implementa- ción de acciones a corto, mediano y largo plazo. La renovación conceptual y metodológica de que es objeto centra la atención en la gestión, en la formulación de políticas públicas coordinadas y en la aplicación de planes, programas, y proyectos en distintas escalas geográficas.

Esta visión del Ordenamiento Territorial requiere operar cambios estructurales, difíciles de lograr por la permanencia de estructuras políticas y administrativas rígidas y por la existencia de poderes con intereses diversos que pugnan para que nada cambie.

El Ordenamiento Territorial no debe depender de los cambiantes humores políticos de los gobiernos y coyunturas electorales, sino que debe ser el resultado de la combinación de fuerzas políticas y sociales para poder implementar acciones consensuadas y coordinadas e intervenir, de manera efectiva y eficiente, en la organización del territorio a través del tiempo. Esto depende del grado de institucionalidad, gobernabilidad y madurez que alcance una sociedad para consolidar la gobernanza como mecanismo de construcción de consen- 
sos y participación ciudadana en los actos de gobierno.

Los que trabajamos en Ordenamiento Territorial durante mucho tiempo hemos estado avocados a aplicar distintas metodologías para elaborar planes, programas o proyectos, pero estos instrumentos no lograrán producir los cambios esperados, si no atendemos aspectos vinculados a las normativas vigentes y la gestión de las políticas públicas.

Con el propósito de ejemplificarlo se analiza, a continuación, un caso: el de Argentina, Estado federativo que define y pone en marcha una Política de Estado de Desarrollo Territorial, luego del cambio de modelo en el país y la crisis económica desatada en el año 2001.

En otra escala de análisis se profundiza en Mendoza, primera provincia argentina que logra sancionar, en 2009, una Ley de Ordenamiento Territorial en la que se prevé el Ordenamiento Territorial, como política del Estado y establece, entre sus principios, el bien común, el equilibrio, la equidad y la sostenibilidad.

\subsection{El estado de situación en Ar- gentina}

El modelo neoliberal instaurado en ese país, en la década de los 90, provoca el uso indiscriminado del territorio, un crecimiento urbano sin control, la competencia inequitativa debida al libre juego oferta-demanda, una pérdida permanente y progresiva de capital natural, cultural y social; el aumento de las desigualdades sociales y la acentuación del proceso de concentración económica y poblacional en determinadas ciudades. Para revertir la situación de conflictos $\mathrm{y}$ atenuar los desequilibrios territoriales y las iniquidades sociales, el Gobierno Nacional, que asume en 2003, encomienda al Ministerio de Planificación Federal, Inversión Pública y Servicios, la construcción de una Política de Estado de Desarrollo Territorial, por implementarse en mediano y largo plazo.

Se concibe al Ordenamiento Territorial como una construcción política y social progresiva en función de la identidad territorial y cultural de cada lugar o jurisdicción del territorio. Su instrumentación se plantea a través de la formulación de una política nacional encargada de gestionar planes, programas $\mathrm{y}$ 
proyectos de desarrollo territorial, tratando de compatibilizar su accionar con las políticas sectoriales. Se pretende que cada organismo incorpore la dimensión territorial en su gestión de gobierno. Se trata de una perspectiva de carácter transversal sobre el conjunto de la gestión socio-gubernamental para permitir superar la actitud de competencia entre provincias $\mathrm{y}$ municipios, a través de modelos de gestión compartida en el territorio. (Ministerio de Planificación Federal, Inversión Pública y Servicios, 2008).

El marco territorial de la Política Nacional de Desarrollo y Ordenamiento Territorial es el de un país equilibrado, integrado, sustentable $\mathrm{y}$ socialmente justo. Como toda política requiere instrumentos para generar los efectos deseados, y es por este motivo que se crea el Sistema Nacional de Desarrollo y Ordenamiento Territorial (SiNDOT), estrategia de intervención permanente que pone en marcha tres componentes básicos para articular y garantizar el logro de los objetivos de la Política Nacional de Desarrollo y Ordenamiento Territorial:
- El Plan Estratégico Territorial Nacional, PET, que define los planes, programas y proyectos a poner en marcha.

- El Sistema de Información, Vinculación y Asistencia Técnica para el Desarrollo y el Ordenamiento Territorial, SIVAT, que genera la información necesaria para la planificación, articula y gestiona las relaciones entre los actores $\mathrm{y}$ asiste en términos técnicos, metodológicos y económicos.

- La Ley Nacional de Desarrollo y Ordenamiento del Territorio, que define las normativas y las reglas de juego de la planificación y los proyectos en marcha.

El Sistema Nacional de Desarrollo y Ordenamiento Territorial avanza en los dos primeros instrumentos: el Plan Estratégico Territorial Nacional, PET, y el Sistema de Información, Vinculación y Asistencia Técnica para el Desarrollo y el Ordenamiento Territorial, SIVAT, pero a más de 10 años de su puesta en marcha no logra los resultados esperados. Son los gobiernos provinciales quienes, siguiendo las directivas del Gobierno Nacional, trabajan en el diagnóstico y 
construcción del modelo deseado, como también en los grandes lineamientos que definen las acciones en el territorio. Pero no todas las provincias hacen partícipe a la sociedad. Se inicia el desarrollo de una infraestructura de datos espaciales, pero no todas las instituciones intervienen en el proceso ni se da un conocimiento real sobre la necesidad de vinculación que debe existir entre el PET y el SIVAT, ni que los mismos forman parte de la política nacional de Ordenamiento Territorial.

La permanencia y estabilidad de ambos instrumentos depende de la Ley Nacional de Desarrollo y Ordenamiento Territorial, la que en el momento no ha sido sancionada debido a la existencia de intereses diversos, lo que se atribuye a la falta de comunicación y participación de las instituciones con competencia en el tema.

Este marco legal debe orientar y regular el proceso de organización y ordenamiento territorial, pero la carencia de este instrumento ha conducido a la permanencia de un marco legal disperso y a la falta de articulación de las acciones. La Constitución Nacional reformada en 1994 establece pautas para orientar la construcción del territorio argentino, a saber:

- El Artículo 75, inc. 19, otorga atribuciones al Gobierno Nacional para proveer el crecimiento armónico de la Nación y promover políticas diferenciadas que tiendan a equilibrar el desarrollo desigual relativo de provincias y regiones.

- El Artículo 124, facilita la posibilidad de que las provincias participen y creen regiones orientadas hacia el desarrollo económico y social. En ellas se podrán crear, además, instituciones orgánicas para el cumplimiento de estos fines. No obstante, sus atribuciones son limitadas, como lo establece el Artículo 26, al prohibir la celebración de tratados parciales de carácter político entre ellas.

- El Artículo 41, otorga a la Nación la facultad de dictar normas que contengan los presupuestos necesarios para la protección, en materia ambiental, respetando las jurisdicciones locales.

- Las provincias son las que dictan las normas ambientales, directamente vinculadas con el buen uso del territorio $\mathrm{y}$, por ende, son estas las que deben 
poner en marcha los planes y programas de ordenamiento territorial.

Un primer problema es el referido a la definición de las competencias jurisdiccionales entre Nación, Provincia y Municipio. Debe recordarse que Argentina es un país federal y, por ende, existen distintos niveles de competencia y autonomía; es decir, de descentralización de poder. Cada provincia dicta su Carta Orgánica o Constitución, la que está condicionada a la Constitución Nacional, de acuerdo con la reforma del año 1994, en 5 temas: el sistema republicano, los principios de derechos y garantías, la educación y justicia y el régimen municipal autónomo. Con respecto a este último punto se debe hacer la salvedad de que el Artículo 123 de la Constitución Nacional, del año 1994, aclara que cada provincia debe asegurar la autonomía municipal reglando su alcance y contenido institucional, político, administrativo, económico y financiero, conforme con lo dispuesto en la nueva Constitución. La mayoría de las provincias modifican su Constitución, cambian la concepción del municipio y definen distintos criterios para otorgar autonomía. Esto representa un problema serio a la hora de definir los alcances de la futura Ley de Ordenamiento Territorial Nacional y puede hacer fracasar el intento de ordenar y articular todas las normativas referentes al territorio. Máxime, cuando existen provincias que no han modificado su Carta Orgánica: Buenos Aires, Santa Fe, Córdoba y Mendoza, las de mayor poder político y económico. Esto constituye limitaciones de tipo político, económico y organizacional para la puesta en marcha e implementación del Ordenamiento Territorial, especialmente en lo referido a la Ley Nacional de Ordenamiento Territorial.

Una ley de este tipo no solo debe tener en cuenta las competencias jurisdiccionales, sino un nuevo concepto de política; uno de carácter transversal a las políticas intersectoriales, con una visión más inter-jurisdiccional que contemple una mayor interacción entre la economía de mercado, los nuevos roles del Estado, las acciones de los sectores privados y las actuaciones entre los sectores públicos y jurisdicciones territoriales. También, debe definir que la modalidad de gestión responda a la propia naturaleza del Ordenamiento Territorial, sistémica e integral, mediante la identificación de los instrumen- 
tos para cada nivel de competencia porque no es el mismo nivel de resolución o escala en la que debe trabajar la provincia o el municipio; requisitos indispensables para poder actuar en forma coordinada e involucrar todos los niveles u oficinas de una institución y a todas las instituciones con injerencia en el tema, incorporando tecnología informacional, una planificación administrativa-contable y una adecuada capacitación del recurso humano interviniente en el proceso. (Gudiño, 2009).

\subsection{El caso de Mendoza, provin- cia argentina}

El detonante que lleva a profundizar en el Ordenamiento Territorial, como política de Estado y forma de gestión integral y coordinada, es la experiencia desarrollada en Mendoza, provincia argentina que, después de más de 18 años de espera y lucha por conseguir una normativa de este tipo, logra sancionar la primera ley en el contexto de la Política Nacional de Desarrollo Territorial en Argentina.

La existencia de proyectos de ley en los que se priorizaba el interés del inversor privado y no el bien común, llevó a movilizar a la ma- yoría de las instituciones para obtener una Ley de Ordenamiento Territorial en la que se plasmara el sentir de una sociedad.

En el intento de dar respuesta a los desequilibrios territoriales de la provincia, más de 12 proyectos de ley de Ordenamiento Territorial no se habían logrado concretar. Los últimos, presentados entre el 2002 y 2005 , fueron los detonantes para que el sector científico y tecnológico elevara un informe interinstitucional que es apoyado por la sociedad en su conjunto. La presión no solo permitió frenar los proyectos, sino archivarlos, por lo que en forma conjunta se trabaja en una nueva propuesta de Ley.

El proceso es iniciado por la Universidad Nacional de Cuyo y participan el sector académico-científico, instituciones del Estado y representantes de la sociedad en su conjunto. En virtud de esta decisión se firma un Acta Acuerdo Interinstitucional, el 28 de diciembre de 2006, entre el Gobierno de la provincia de Mendoza, las Comisiones Legislativas, el Sector Académico y Científico, y otras instituciones para tal fin. 
El trabajo exige un gran esfuerzo de articulación entre instituciones gubernamentales, municipios y organizaciones no gubernamentales. A través de una importante campaña de difusión se comunica los avances realizados, lo que permite a la sociedad avalar los resultados alcanzados ${ }^{2}$.

La Universidad, había generado una sinergia en la comunidad y las instituciones para iniciar el camino hacia la gobernanza y para transformar al Ordenamiento Territorial en una verdadera política de Estado; sin embargo, el proceso no logra afianzarse debido a la pérdida de liderazgo de la Universidad, la permanencia de estructuras de poder en el propio Estado y la existencia de fuerzas de intereses que pugnan para que nada cambie.

El Ejecutivo provincial presenta el anteproyecto a la Legislatura de Mendoza, en el año 2007, y luego de dos años de consultas y correcciones es aprobado por unanimidad de ambas Cámaras y sancionado como Ley No 8051 de Ordenamiento Territorial y Usos del

2 Universidad Nacional de Cuyo. (2009). Anteproyecto Ley de Ordenamiento Territorial y Usos del Suelo. Marco Regulatorio. 1a ed. Mendoza, Argentina: Universidad Nacional de Cuyo.
Suelo, en mayo de 2009 (Legislatura, 2009).

La normativa prevé el Ordenamiento Territorial, como política del Estado; plantea la necesidad de consolidar la gobernabilidad y define mecanismos de participación y patrones de interacción entre actores estratégicos.

El propósito es generar las condiciones para que los ciudadanos contribuyan al cumplimiento del bien común e interactúen, y sean partícipes proactivos y responsables, mediante la opinión informada y fundada en todas las etapas del Ordenamiento Territorial. Tendiente a ello se definen mecanismos de educación, información, integración y participación a través de publicidad, consultas y audiencias públicas, así como acciones de amparo.

La normativa prevé, además, instrumentos jerarquizados conforme con las competencias jurisdiccionales y con la existencia de distintas escalas geográficas. Se diferencian los contenidos del Plan Provincial y de los Planes Municipales de Ordenamiento Territorial conforme con las competencias dadas por la Constitución provin- 
cial, los que se sustentan en la conformación y uso de un Sistema de Información Territorial provincial, de acceso público y gratuito. Como mecanismos de control se definen: la Evaluación de Impacto Territorial, EIT, como complemento de la Evaluación de Impacto Ambiental, EIA, y las Auditorías Externas de Impacto Territorial, como procedimiento para controlar la implementación de los Planes de Ordenamiento Territorial, sus Programas y Proyectos. Incorpora, además, otros instrumentos para permitir la captación de recursos y canalización y direccionamiento de la inversión con el propósito de recuperar plusvalías y promover o desalentar actividades en el territorio, según criterios de equidad y sostenibilidad.

Se opta un modelo de gestión innovador, sustentado en la conformación de un sistema interinstitucional de coordinación y decisión en el que deben participar los diferentes actores implicados. Esto significa cambiar, parcialmente $\mathrm{y}$ en forma gradual, la metodología de trabajo, con el involucramiento de lo social, lo político, lo económico, lo ambiental, como una unidad indisoluble en el territorio. Se pone énfasis en las vinculaciones múltiples, dinámicas y cambiantes de la actuación de los organismos que participan en el sistema.

Si bien la Ley, en su concepción, incluye todos los medios para producir una verdadera transformación estructural en la gestión, es muy poco lo que se ha avanzado en su reglamentación y aplicación, debido a la existencia de estructuras de poder en el mismo Estado e intereses económicos que frenan el proceso y que luchan para que nada cambie.

En el anteproyecto se proponía la creación de una Unidad de Ejecución, como autoridad de aplicación, de carácter descentralizado y autárquico, con personería jurídica, capacidad de decisión y recursos financieros propios, lo que no fue aceptado ni por gobierno ni por legisladores. La unidad fue reemplazada por una Agencia que está dentro de la estructura del Gobierno Central lo que ha significado que la designación de personal sea más política que técnica, y que las decisiones queden en manos del gobierno de turno. Esto demuestra la falta de voluntad política para destrabar la burocracia de la administración pública. También debilita el accionar del Consejo de Or- 
denamiento Territorial, organismo creado a partir de la Ley que debería estar conformado por representantes de municipios, organismos científicos, académicos, colegios profesionales y organizaciones de la sociedad civil y que en la actualidad no tiene representatividad de todos los involucrados en la toma de decisiones sobre el territorio, tal como lo exige la Ley, espacio que ha sido cooptado por funcionarios del gobierno provincial.

La Ley $\mathrm{N}^{\circ}$ 8051/09 de Ordenamiento Territorial y Usos, en su Artículo 1, sobre objeto y fines del Ordenamiento Territorial, establece lo siguiente:

La presente ley tiene por objeto establecer el Ordenamiento Territorial como procedimiento político administrativo del Estado en todo el territorio provincial, entendido éste como Política de Estado para el Gobierno Provincial y el de los municipios. Es de carácter preventivo y prospectivo a corto, mediano y largo plazo, utilizando a la planificación como instrumento básico para conciliar el proceso de desarrollo económico, social $y$ ambiental con formas equili- bradas y eficientes de ocupación territorial.

El artículo mencionado considera al Ordenamiento Territorial, como una forma de planificación del territorio y un instrumento básico para el desarrollo. Destaca dos conceptos: primero, define el Ordenamiento Territorial como procedimiento administrativo; es decir, centra su atención en la gestión, y segundo, lo considera una política de Estado por lo que, además del gobierno provincial y municipal, está implícita la participación de las diferentes instituciones que componen la sociedad mendocina; exigencia que en la realidad no se cumple.

Una serie de hechos demuestran que no ha logrado convertirse en una política de Estado. La inercia en la gestión acentúa los problemas relacionados con la organización y uso del territorio; los mecanismos de control continúan siendo débiles; la Agencia de Ordenamiento Territorial tiene una capacidad de decisión reducida y los recursos financieros que estaban especificados en la Ley son destinados a otros fines; la reglamentación y aplicación de la Ley se encuentra demorada debido a estructuras de 
poder e intereses políticos y económicos que frenan el proceso.

Es decir que no existe voluntad política de parte de quienes tienen las mayores responsabilidades por asumir, lo que debilita la institucionalidad y gobernabilidad. Tampoco, se hace partícipe a otros actores no gubernamentales, por lo que no se respeta el espacio de la participación ciudadana en el Consejo de Ordenamiento Territorial, mientras que la mayor representatividad la tienen las instituciones del propio Estado, lo que dista mucho de lograr una verdadera gobernanza.

\section{Reflexiones finales}

De nada vale tener buenos documentos técnicos que no puedan ser aplicados, ni generar leyes que no se cumplen, ni seguir formulando políticas que resultan ineficientes para mejorar las condiciones de vida de la población. Las esperanzas están puestas en el Ordenamiento Territorial, porque no se han logrado minimizar los impactos ocasionados por la concentración de poder político y económico, en lo social, ambiental y territorial. Esta especialidad lleva a profundizar en el Estado, como entidad política y administrativa, en las competencias jurisdiccionales y en su relación con las escalas geográficas, como también en la diferenciación existente entre la política de Estado y las políticas públicas para poder intervenir en el territorio.

El análisis crítico e interpretativo sobre el proceso de planificación América Latina, como también el desarrollo de la experiencia de Argentina y Mendoza, en particular, señalan la necesidad de mayor institucionalidad, gobernabilidad y gobernanza para que el Ordenamiento Territorial se transforme en una política de Estado. Si esto no se consigue, los cambios que se necesitan operar en la gestión, no serán efectivos y no se podrán conciliar posiciones entre los intereses y poderes existentes en el territorio.

Una política de Estado se construye a partir de consensos o, por lo menos, definiendo compromisos que deben plasmarse en acuerdos formales para llegar a un gran acuerdo, perdurable en el tiempo; debe ponerse por delante el interés común de la sociedad y los principios y fines del Ordenamiento Territorial. 
El territorio demanda la coordinación interinstitucional para poner en marcha y asegurar, en el tiempo, la aplicación de instrumentos territoriales (planes, programas, proyectos), económicos y de gestión. La convergencia de actores y poderes en el territorio requiere la resolución de conflictos y la generación de consensos, única manera de construir un proyecto común y minimizar la incertidumbre en la toma de decisiones.

\section{Referencias}

Becerril-Pauda, M. \& Garcés, C. (2004). Contribuciones de la CEPAL en los estudios del fenómeno urbano-metropolitano, 1950-1990. Revista de Estudios Regionales, (70), 142172.

Boisier, S. (1985). Un difícil equilibrio: centralización y descentralización en la planeación regional, Revista el Trimestre Económico, LII(205), 67-85.

Consejo de Europa. (1983). Carta Europea de Ordenación del Territorio. Torremolinos, España: Conferencia Europea de Ministros Responsables de la Ordenación del Territorio.

Constitución de la Nación Argentina. (1994, 22 de agosto). Recuperado de: http://www.senado. gov.ar/deInteres

Comisión de Desarrollo y Medio Ambiente de América Latina y El Caribe (1991). Nuestra Propia Agenda sobre Desarrollo y Medio Ambiente. Instituto Interamericano de Derechos Humanos, 13, 267-288.

Coraggio, J.L. (1981). Posibilidades de una planificación territorial para la transición en América Latina. Cuadernos de la Sociedad Venezolana de Planificación, 15(3), 153-155.

Cueto, W. \& Guardamagna, M. (2011) ¿Hay políticas de Estado en la Argentina? Aproximaciones a un concepto. Ponencia presentada en el X Congreso Nacional de Ciencia Política, Córdoba, Argentina. Sociedad Argentina de Análisis Político y Universidad Católica de Córdoba.

De Mattos, C.A. (1986). Paradigmas, modelos y estrategias en la práctica latinoamericana de planificación regional. Revista Pensamiento Iberoamericano, 10, 13-38.

De Mattos, C.A. (2005). De la planificación a la gobernanza: hacia un nuevo modo de gestión urbana. Revista Ciudades, 66. 
Franco, R. \& Székely Pardo, M. (Coord.). (2010). Institucionalidad social en América Latina. Colección Documentos de proyectos. Proyecto Género, población y desarrollo (RLA/6P41A), Santiago de Chile: CEPAL/UNFPA.

Gudiño, M.E. (2009): Instrumentos para la gestión del territorio. Ley de Ordenamiento Territorial y sistemas de información geográfica. Ponencia presentada en las Jornadas Regionales de Información Geográfica y Ordenamiento Territorial, Ministerio Secretaría General de la Gobernación, Proyecto SIT Santa Cruz. Díaz B.G. y Calviño P. (Compiladores), pp. 22-47.

Gudiño, M.E., Berón, N. \& Rapali, N. (2013). Ciudad intermedia, territorio y planificación. Tres temas a incluir en la Agenda Futura. Ponencia presentada en el Seminario Internacional 20 Aniversario de la Red de Investigadores sobre Globalización y Territorio (RII), Monterrey, Nuevo León, México.

Isuani, E. (1984). Tres enfoques sobre el concepto de Estado (Trad. Nelson Cardozo). Revista de Ciencia Política, 27.

Legislatura Provincia de Mendoza, Argentina (2009, 5 de mayo). Ley de Ordenamiento Territorial y Usos del Suelo. (Ley 8051). DO: 28407.

Massiris-Cabeza, Á. (2002). Ordenación del Territorio en América Latina. Revista Scripta Nova, $V I(125)$.

Massiris-Cabeza, Á. (2008). Gestión del Ordenamiento Territorial en América Latina: Desarrollos recientes. Revista Proyección, 1(4).

Méndez, R. \& Molinero, F. (1984). Geografía y Estado. Introducción a la Geografía Política. Madrid: Cincel.

Ministerio de Planificación Federal Inversión Pública y Servicios. (2008). Argentina 2016. Política y Estrategia Nacional de Desarrollo y Ordenamiento Territorial. Buenos Aires: Ministerio de Planificación Federal Inversión Pública y Servicios.

Montes Lira, P. (2001). El Ordenamiento territorial como opción de politicas urbanas regionales en América Latina y el Caribe. Serie Medio Ambiente y Desarrollo, Santiago, Chile: CEPAL, $\mathrm{N}^{\circ} 45$.

Natanson, J. (2008, 29 de junio). ¿Qué es, en realidad, una política de Estado? Página 12. Recuperado de: http://www.pagina12.com.ar

Romero, L. A. (2010, 21 de agosto). Cómo crear políticas de Estado. Diario Perfil. Recuperado de: http://www.perfil.com

Rulli, J. (2006). Producir soja como política de Estado. Recuperado de: http://www.ecoportal. net/Temas_Especiales/Transgenicos/Producir_soja_como_politica_de_Estado. [Accedido el $15 / 08 / 13$ ] 
Taylor, P. J. (1994). Geografía Política. Economía Mundo, Estado nación y localidad. Madrid: Trama Editorial.

Universidad Nacional de Cuyo. (2009). Anteproyecto Ley de Ordenamiento Territorial y Usos del Suelo. Marco Regulatorio. 1a. ed. Mendoza, Argentina: Universidad Nacional de Cuyo.

Vega Mora, L. (2008). Gestión medioambiental sostenible: un enfoque sistémico para la protección global e integral del medioambiente. España: Tercer Mundo Editores.

Weber, M. (2007). La ciencia como profesión y la politica como profesión. 3a. ed. Madrid, España: Espasa Calpe. S.A.

Recepción: 11 de noviembre de 2014

Evaluación: 27 de febrero de 2015

Aprobación: 4 de mayo de 2015 